\title{
The Quality of Drinking Water for Cattle; It's A Pity Cows aren't Capable to Complain Verbally
}

\section{Jos J Vermunt*}

Adjunct Professor (Cattle Health and Production), College of Public Health, Medical and Veterinary Sciences, James Cook University, Townsville, QLD, Australia

*Corresponding author: Jos J Vermunt, 80 Russell Robertson Drive, Havelock North 4130, New Zealand.

Received date: 1 September, $2021 \mid$

Accepted date: 11 September, $2021 \mid$

Published date: 14 September, 2021

Citation: Jos J Vermunt (2021) The Quality of Drinking Water for Cattle; It's A Pity Cows aren't Capable to Complain Verbally. J Clin Vet Res 1(1). doi https://doi.org/10.54289/JCVR2100103

Copyright: (C) 2021 Jos J Vermunt, This is an open-access article distributed under the terms of the Creative Commons Attribution License, which permits unrestricted use, distribution, and reproduction in any medium, provided the original author and source are credited.

\section{Opinion}

The necessity of water for support of life is largely unquestioned. Of all the nutrients indispensable for life, water is second only to oxygen in importance. However, this commonplace fact is often not well appreciated. From a nutritional point of view, water is the most critical nutrient for dairy cattle, and is required for numerous important physiological functions. As a whole, the water content of the animal body ranges from 55 to $67 \%$ of body weight. Water is the main component of milk, saliva, and waste products, such as urine and faeces [1]. Water is further lost from the lungs during breathing or panting, by evaporation from the skin, and sweating. Hence, dairy cattle have a large daily requirement for water, most of it being obtained from free water intake. Because dairy cattle suffer more quickly from an inadequate water intake than from a deficiency of any other nutrient, clean, fresh drinking water should be available at all times.

The water needs of a dairy cow depend on several factors, including its production level, body weight, and food intake, the moisture level of the diet, and the ambient temperature and humidity. There are two issues involved in providing water to stock on a dairy farm, one is quantity, the other being quality. Lactating dairy cows, in particular, need ample water, since the major component of milk is water, and cows need to drink within one hour of being milked [2]. Milk production and food intake will be depressed if free access to water is not allowed.
A lack of water can also cause loss in body condition, mainly due to the loss in appetite. Therefore, all water losses must be replaced if the animal is to remain in water balance and not become dehydrated.

Water intake is closely related to feed intake, and thus animal productivity [3]. Cattle are sensitive to the palatability of water and prefer to drink clean water without contamination. Cows will consume 3 to $5 \mathrm{~L}$ of water for each kilogram of dry matter consumed, plus additional water for milk production. Thus, cows producing about $35 \mathrm{~L}$ of milk may drink about $135 \mathrm{~L}$ of water per day [4]. On succulent feeds, water consumption will be less. The issue of drinking water quantity is especially valid during the summer months and on very warm days. Under those conditions, the amount of water intake will increase significantly; it may be tripled [4], and milking cows may drink at a rate of up to $17 \mathrm{~L}$ per minute [5]. Clearly, it is important to provide dairy cattle with an adequate supply of water. However, the voluntary intake of water may be much reduced when only poor-quality water is being offered [6]. Although water is regarded as a primary nutrient required in large quantities by dairy cattle, it is seldom assessed from a quality point of view. One reason for this may be that there are no specific standards for water quality; guidelines usually being derived from the standards of drinking water for humans. There are also a very limited number of controlled studies 
where the effects of water quality on animal performance were quantified [3]. However, there may be situations in the field where the quality of drinking water has the potential to significantly limit animal performance. For example, poortasting water may lead to a decrease in water intake, which, in turn, will reduce feed intake and, as a consequence, lower milk production. It may also contribute to health problems.

Water quality has been defined in a number of ways. Thompson [7] suggested that at least five criteria should be used to evaluate water quality. These include: (i) organoleptic properties - primarily taste and smell; (ii) physical/chemical properties - including factors like total dissolved solids, $\mathrm{pH}$ and hardness; (iii) levels of compounds in the water - e.g., nitrates, sulphates and iron; (iv) the presence of toxic compounds - e.g., lead and mercury; and (v) the presence of micro-organisms - including bacteria, viruses, protozoa, and parasites. Others suggest that good-quality water should be defined by factors such as taste, smell, turbidity, electrical conductivity, and the presence or absence of certain substances [8].

Several years ago, the need for fresh, clean drinking water was brought to my attention when I was examining a "downer cow". I happened to notice that many of the other cows in the fresh-cow herd were reluctant to drink from the trough, which was available in the paddock. First, they kind of "smelled" the water, then carefully tasted it, after which they let the water run from their mouth, while backing off at the same time. The trough in question contained a cloudy, pink-coloured liquid, which turned out to be a mixture of bore water, bloat remedy, magnesium sulphate, copper sulphate, and selenium. After some calculating, it turned out that magnesium sulphate had been added to the drinking water system at a rate of 120 grams per cow per day, which was twice the recommended maximum dose for water treatment. Usually, magnesium oxide is used to supplement cows with magnesium during the winter/spring period. This magnesium compound is then mixed in with maize silage, and subsequently fed out in feed bunks. In this particular case, the farmer thought that there was still a perceived need to continue supplementing with magnesium after the maize silage had run out, and he had opted for a 'decent amount' of magnesium sulphate to be administered via the drinking water system. This incident then provoked an interesting conversation regarding the importance of fresh, clean drinking water.

Blood tests carried out on 10 cows in the fresh-cow herd showed that the average serum magnesium level was 0.86 $\mathrm{mmol} / \mathrm{L}$ (ranging from 0.76 to $1.02 \mathrm{mmol} / \mathrm{L}$ ). While the amounts of minerals (magnesium sulphate in particular) added to the drinking water of these cows were perhaps not detrimental to their overall health, they probably were high enough to reduce the water's palatability. Neither selenium nor copper sulphate, when added to the drinking water at the correct dose rates, presents a health risk to dairy cattle. However, the presence of these minerals may have contributed to the water's palatability issue.

In the past, the only compound added to the drinking water of dairy cattle has been some form of bloat control product, and then only during periods of moderate to high risk of bloat occurring. Nowadays, almost any product or compound, which is water soluble, may be dispensed through the drinking water system, including bloat remedies, various macro- and trace-mineral compounds, ionophores (e.g., monensin sodium), as well as masking agents.

In Australasia, during the risk period of sporidesmin toxicity ("facial eczema") occurring, extremely high amounts of zinc sulphate need to be dispensed continuously through the drinking water system in order to prevent and control this secondary photosensitisation disease. High concentrations of sulphates have a laxative effect in cattle, but, normally within one week, animals get accustomed to the medicated water, and "diarrhoea" is no longer apparent. However, in the long term, sulphate water can also have a subtle, but deleterious effect on cattle, i.e., those consuming water that contains high levels of sulphate are reported to eat less feed and drink less water [9].

Like people, cows simply may not like the taste of water that contains various animal remedies and/or variable amounts of minerals - especially when those amounts exceed "normal values". That, in turn, could cause cows to drink less water than what is required and, consequently, impact on their milk production. In case described above, the average daily milk production increased by close to $2 \mathrm{~L}$ per cow as soon as the addition of magnesium sulphate in the drinking water was discontinued, and pasture dusting with magnesium oxide was 
taken up.

Cows require clean and fresh water, not heavily mineralised or treated with other animal remedies. Because of their innate nature, most additives will limit the want for, and amount of, water consumption. I really challenge dairy veterinarians to actually taste the "cocktails" that are from time to time prescribed for some of their clients' dairy cows. If you wouldn't drink the water those cows are expected to drink, then why should they? We should assess first whether or not there is a real, and not perceived, need for minerals or other additives to be fed. If so, and whenever possible, alternative but equally effective - supplementing routes should be used if supplementation is indicated.

\section{References}

1. Murphy MR. (1992) Water metabolism of dairy cattle. J Dairy Sci. 75(1): 326-333.

2. Greenough PR (2003) Production medicine - is it a matter for veterinarians? The Veterinary Journal 165(3): 188-189.

3. Schütz K (2012) Effects of providing clean water on the health and productivity of cattle. AgResearch, Report for Northland Regional Council.
4. Amstutz HE (1998) Nutrition: Cattle. In: Aiello SE (ed), The Merck Veterinary Manual, $8^{\text {th }}$ edn. Merck \& Co Inc. Whitehouse Station USA.

5. Dado RG, Allen MS (1994) Variations in the relationships among feeding, chewing, and drinking variables for lactating dairy cows. J Dairy Sci 77(1): 132-137.

6. Cardot V, Roux YL, Jurjanz S. (2008) Drinking behavior of lactating dairy cows and prediction of their water intake. J Dairy Sci 91(6): 2257-2264.

7. Thompson LJ (1997) Water quality effects on cow health and production. Proceedings of the National Mastitis Council Meeting, Syracuse, NY, USA.

8. Socha MT, Tomlinson DJ, DeFrain JM. (2009) Variability of water composition and potential impact on animal performance. Pp 56-70. Proc Calif Anim Nutr Conf, Fresno, Ca., USA.

9. Weeth HJ, Hunter JE. (1971) Drinking of sulphatewater by cattle. J Anim Sci 32(2): 277-281. 